Article

\title{
First Trimester Maternal Vitamin D Status and Risks of Preterm Birth and Small-For-Gestational Age
}

\author{
Isabelle Monier ${ }^{1,2, *(1)}$, Amandine Baptiste ${ }^{3}$, Vassilis Tsatsaris ${ }^{4}$, Marie-Victoire Senat ${ }^{5}$, \\ Jacques Jani ${ }^{6}{ }^{\circledR}$, Jean-Marie Jouannic ${ }^{7} \mathbb{D}$, Norbert Winer ${ }^{8}$, Caroline Elie ${ }^{3}$, \\ Jean-Claude Souberbielle ${ }^{9}$, Jennifer Zeitlin ${ }^{1}$ (D) and Alexandra Benachi ${ }^{2}$ \\ 1 Université de Paris, CRESS, INSERM, INRA, F-75004 Paris, France; jennifer.zeitlin@inserm.fr \\ 2 Department of Obstetrics and Gynaecology, Antoine Béclère Hospital, AP-HP, University Paris Saclay, \\ F-92140 Clamart, France; alexandra.benachi@aphp.fr \\ 3 URC/CIC Paris Descartes Necker Cochin, Necker-Enfants Malades Hospital, AP-HP, F-75015 Paris, France; \\ amandine.baptiste@aphp.fr (A.B.); caroline.elie@aphp.fr (C.E.) \\ 4 Department of Obstetrics, Cochin Hospital, AP-HP, Paris-Descartes University, F-75014 Paris, France; \\ vassilis.tsatsaris@aphp.fr \\ 5 Department of Obstetrics and Gynecology, Bicêtre Hospital, AP-HP, Université Paris Saclay, F-94270 Kremlin \\ Bicêtre, France; marie-victoire.senat@aphp.fr \\ 6 Department of Obstetrics and Gynecology, University Hospital Brugmann, Université Libre de Bruxelles, \\ B-1000 Brussels, Belgium; jacques.jani@chu-brugmann.be \\ 7 Fetal Medecine Department, Armand Trousseau Hospital, AP-HP, UPMC-Sorbonne Université, \\ F-75012 Paris, France; jean-marie.jouannic@aphp.fr \\ 8 Department of Obstetrics and Gynecology, University Hospital of Nantes, CIC Mere enfant Nantes, NUN, \\ INRA, UMR 1280, Phan, Nantes University, F-44000 Nantes, France; norbert.winer@chu-nantes.fr \\ 9 Laboratoire d'Explorations Fonctionnelles, Necker-Enfants malades Hospital, AP-HP, F-75015 Paris, France; \\ souberjc@outlook.fr \\ * Correspondence: isabelle.monier@inserm.fr; Tel.: +33-(0)1-7172-2992
}

Received: 17 October 2019; Accepted: 6 December 2019; Published: 13 December 2019

check for updates

\begin{abstract}
Maternal 25-hydroxyvitamin D (25-OHD) deficiency during pregnancy may increase the risk of preterm and small-for-gestational age (SGA) birth, but studies report conflicting results. We used a multicenter prospective cohort of 2813 pregnant women assessed for 25-OHD levels in the first trimester of pregnancy to investigate the association between maternal 25-OHD concentrations and risks of preterm birth ( $<37$ weeks) and SGA (birthweight $<10$ th percentile). Odds ratios were adjusted (aOR) for potential cofounders overall and among women with light and dark skin separately, based on the Fitzpatrick scale. 25-OHD concentrations were $<20 \mathrm{ng} / \mathrm{mL}$ for $45.1 \%$ of the cohort. A total of $6.7 \%$ of women had a preterm birth. The aOR for preterm birth associated with the 1st quartile of 25-OHD concentrations compared to the 4 th quartile was 1.53 (95\% confidence interval (CI): 0.97-2.43). In stratified analyses, an association was observed for women with darker skin (aOR $=2.89$ (95\% CI: $1.02-8.18)$ ), and no association with lighter skin. A total of $11.9 \%$ of births were SGA and there was no association overall or by skin color. Our results do not provide support for an association between maternal first trimester 25-OHD deficiency and risk of preterm or SGA birth overall; the association with preterm birth risk among women with darker skin requires further investigation.
\end{abstract}

Keywords: vitamin D; 25-hydroxyvitamin D; pregnancy; preterm birth; small-for-gestational age; skin color

\section{Introduction}

Vitamin $\mathrm{D}$ is generated in the liver and then in the kidneys and is commonly assessed by the measurement of 25-hydroxyvitamin D (25-OHD) levels [1]. Vitamin D has an important role in bone 
and mineral metabolism and was historically used for rickets prevention. During pregnancy, vitamin $\mathrm{D}$ may play a role in the prevention of infections and fetal bone growth [2-4]. Therefore, vitamin D supplementation for pregnant women has been seen as a potential intervention to reduce the risk of preterm birth and small-for-gestational age (SGA) that are main causes of perinatal morbidity and mortality [5-7]. One hypothesis focuses on the role of maternal vitamin D in placenta inflammation and the development of bacterial vaginosis, which are known to be associated with the risk of preterm birth $[2,3]$. Vitamin D may also have an effect on fetal bone development and fetal growth. One study found that the expression of placenta vitamin D receptor was decreased among pregnancies with fetuses with growth restriction [8].

Some research has provided evidence for the existence of an association between vitamin D and preterm and SGA birth, but results have not been consistent. Meta-analyses of randomized controlled trials have reported an association between lower maternal vitamin $\mathrm{D}$ concentrations and an increased risk of preterm birth and low birthweight $<2500 \mathrm{~g}$ [9], a higher risk of SGA but not preterm birth [10], and no association with either outcome [11]. Some observational studies found that vitamin D deficiency increased the risk of preterm birth [12,13] or SGA [14-17], whereas others have not [18-21]. Many of these studies have methodological limitations, however. Vitamin D status in the first trimester is of the most interest for prevention, but vitamin D is often measured later in pregnancy [14,16,22-24]. Further, most observational studies have been single-centre studies $[12,14,15,18-20]$ or were not designed for the assessment of maternal vitamin D status during pregnancy $[12,14,15,19,22]$. Several studies also found that the relationship between maternal vitamin D concentrations and the risk of preterm and SGA birth differed for white and black women, based on race and ethnicity used as a proxy for skin color [13-15,25]. Skin color is one factor that is highly related to vitamin D absorption, with a higher risk of vitamin D deficiency in dark-skinned women [1,26], but this information has rarely been available in these research studies [9].

In this study, our aim was to investigate the association between maternal first trimester vitamin $\mathrm{D}$ concentrations and the risks of preterm and SGA birth using a large prospective cohort designed for the assessment of maternal vitamin D during pregnancy which includes 25-OHD concentrations measured between 10 and 14 weeks of gestation as well as data on skin color.

\section{Materials and Methods}

\subsection{Study Design}

The FEPED study is an observational prospective cohort conducted from April 2012 through July 2014 in five French and one Belgium maternity units [27,28]. The primary aim of this study was to assess the prevalence of vitamin D deficiency over the course of pregnancy and the association between vitamin D concentrations and preeclampsia [28]. Eligible women were aged over 18 years old with a singleton pregnancy between 10 and 14 weeks of gestational age at enrolment. Enrolment took place at the first prenatal visit in the maternity units participating in the study. Women were not eligible if they met one of the following criteria: hypercalcemia $>2.65 \mathrm{mmol} / \mathrm{L}$ or other known phosphocalcic diseases, hypertension at the beginning of the pregnancy (defined as a systolic blood pressure $>140 \mathrm{mmHg}$ or a diastolic blood pressure $>90 \mathrm{mmHg}$ ), renal insufficiency (creatinine concentration $>120 \mu \mathrm{mol} / \mathrm{L}$ ), bone disease, Lithium treatment, bowel malabsorption or kidney stone disease. Each woman received information and provided written consent to participate in the study. The study was approved by the National Data Protection Authority (CNIL no. 911432), and the committee for the protection of people participating in biomedical research (2011/13 NICB; 31/05/2011).

At enrolment, a physician completed a questionnaire to ensure that women met the inclusion criteria. In this questionnaire, skin color was assessed using the Fitzpatrick scale [29]. The Fitzpatrick classification includes six skin types according to phenotype (skin, hair and eyes color) and skin tolerance to ultraviolet radiation exposure, based on a brief interview with the women. Type I indicates pale skin and type VI very dark skin. Women were subsequently grouped into those with lighter skin 
(skin type I through IV) and those with darker skin (skin type from V to VI), in line with previous investigations [26,28].

After delivery, sociodemographic and clinical data were abstracted from medical records by personnel trained for the study. Sociodemographic maternal characteristics included parity, maternal age, height, prepregnancy weight, ethnicity and smoking status before and during pregnancy. Information was also collected on medical and obstetrical history (diabetes, chronic hypertension, auto-immune diseases, obstetrical history of SGA infant, preterm birth, stillbirth and pre-eclampsia), complications of the current pregnancy (pre-eclampsia, HELLP syndrome, gestational diabetes), the delivery and the infant's health status at birth.

\subsection{Study Population}

In the original cohort, 3129 women were included; 36 women were subsequently excluded because they were discovered to have an exclusion criteria or had no blood test to measure 25-OHD concentrations. We further excluded women who delivered outside of participating maternity units or were lost to follow-up $(n=183)$, miscarriages, abortions and terminations of pregnancy before 22 weeks of gestation $(n=36)$. Cases with missing data for birthweight $(n=14)$, gestational age $(n=1)$, infant sex $(n=5)$ and 25-OHD maternal concentrations in the first trimester of pregnancy $(n=41)$ were also excluded. The study population included 2813 women. (Figure 1)

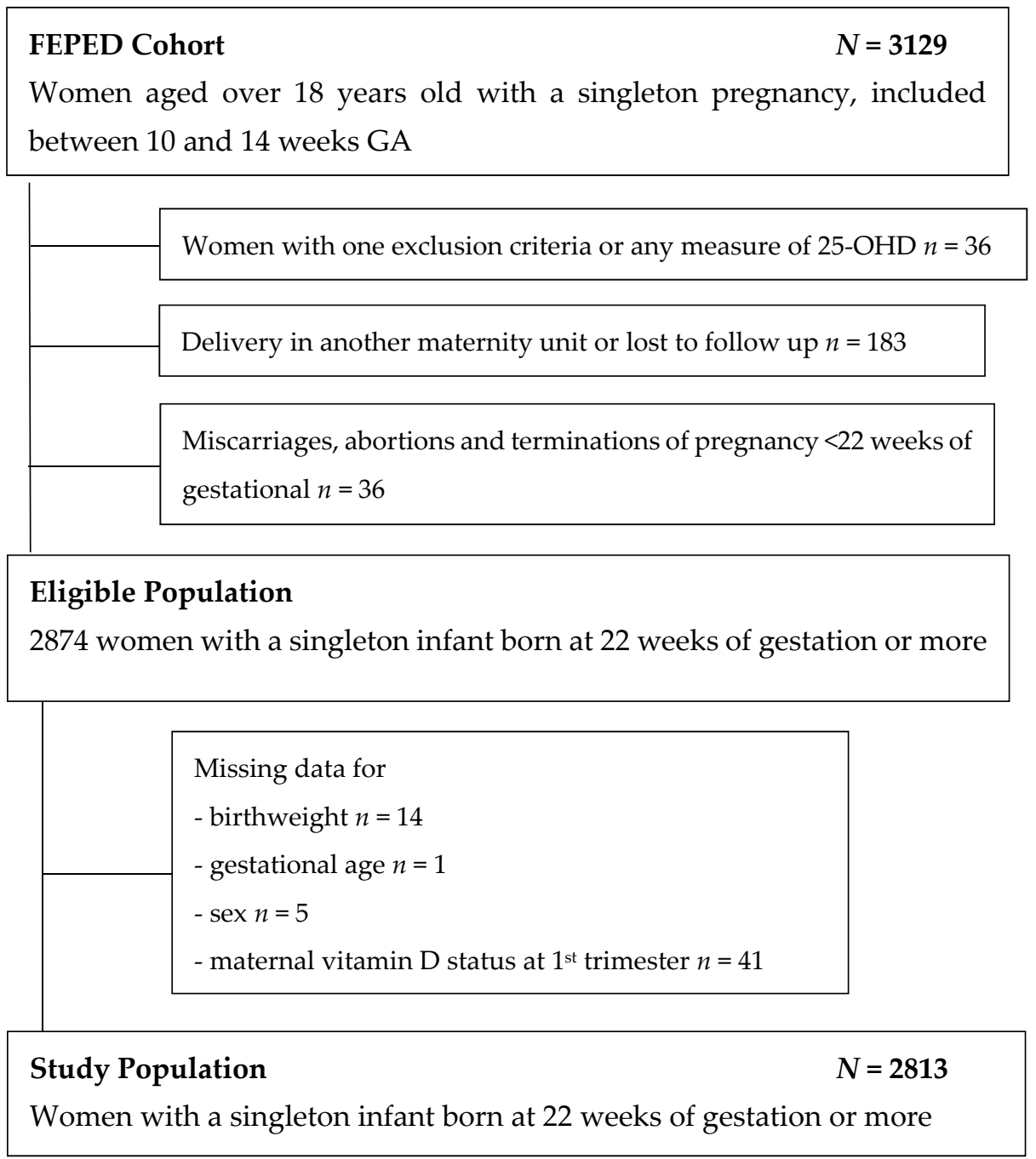

Figure 1. Flow chart. 


\subsection{Definition of Outcomes}

Preterm birth was defined as a delivery $<37$ weeks of gestation and SGA as a birthweight $<10$ th percentile according to intrauterine growth reference adapted to the French population [30]. We selected these outcomes, as opposed to gestational age or birthweight, as continuous variables, because they have been used in most studies reported in systematic reviews [9-11]. In France, the first routine ultrasound is recommended between $11+0$ and $13+6$ weeks of gestation for pregnancy dating, based on the crown-rump length (CRL), in accordance with the date of the last menstrual period (LMP). In case of disagreement between CRL and the LMP, CRL is used for pregnancy dating [31].

\subsection{Maternal 25-OHD Serum}

All women participating in the study provided blood samples between 10 and 14 weeks of gestation to measure their 25-OHD concentration, which is the best assessment of vitamin D levels in the human body [1]. Information was recorded on gestational age and season at blood draw. All blood samples were centrifuged and stored locally at $-20^{\circ} \mathrm{C}$ and transferred monthly to the department of Physiology of Necker University hospital (Paris, France). Serum 25-OHD levels were measured by radioimmunoassay (RIA) after pretreatment with acetonitrile (Diasorin, Stillwater, MN, USA) [32]. The limit of quantification determined in our laboratory was $4 \mathrm{ng} / \mathrm{mL}$ and the inter-assay coefficient of variation was $<10 \%$. Quality control was ensured through the participation of this laboratory in the DEQAS quality assurance program.

Despite recommendations on the prevention of vitamin D deficiency from the Institute of Medicine and the US Endocrine Society [33,34], there is no consensus on the definition of vitamin D deficiency [35]. We choose to assess maternal 25-OHD concentrations using two methods: (1) using clinical cut-offs based on the US Endocrine Society recommendations [33] $(<20,20-29,30+\mathrm{ng} / \mathrm{mL})$ and (2) in quartiles of the observed distribution. In France and in Belgium, women are not routinely supplemented with vitamin $\mathrm{D}$ before pregnancy [36].

\subsection{Statistical Analysis}

We described the maternal characteristics of the study population and estimated means and standard deviations (SD) of maternal 25-OHD concentrations in the first trimester overall and by maternal characteristics. We then calculated the proportion of women with 25-OHD concentrations $<20 \mathrm{ng} / \mathrm{mL}$ in the first trimester of pregnancy by selected characteristics. Based on the scientific literature and biological plausibility, we selected co-variables as possible confounders of the association between vitamin D concentrations and preterm birth and SGA, including maternal age, parity, pre-pregnancy body mass index (BMI), smoking, medical and obstetrical history. We also included season at blood draw, skin color and ethnicity, since these were hypothesized to be strongly related to vitamin D status and there is increasing evidence of an association with perinatal outcome. Seasonal variations in respiratory and viral infections, as well as in the temperature, impact on preterm birth [37-40], while skin color is related to ethnicity, which has an independent effect on preterm birth and SGA; recent research suggests that skin tone may also be directly relevant to the investigation of perinatal outcomes [41-43].

Logistic regression was also used to estimate adjusted odds ratios (aOR) for preterm and SGA birth for the groups, defined by quartile and clinical cutoffs. Based on the hypothesis that there may be an interaction between our outcomes and skin color, we carried out analyses stratified by skin color according to the Fitzpatrick scale [29]. As a sensitivity analysis, models were run with gestational age and birthweight as continuous variables. Finally, in order to assess whether our cut-off points adequately described risk patterns, we used restricted cubic splines with four knots to represent the association between 25-OHD maternal concentrations and the risk of preterm and SGA birth in the overall sample and by skin color separately. Analyses were performed using Stata 13.0 software (StataCorp LP, College Station, TX, USA). 


\section{Results}

\subsection{Maternal Characteristics of the Study Population}

Table 1 presents the maternal characteristics of the study population and the means of maternal 25-OHD concentrations in the first trimester of pregnancy. Mean 25-OHD concentration was $22.2 \pm 10.3 \mathrm{ng} / \mathrm{mL}$ and differed by maternal characteristics, as well as season of blood draw. Women with light skin (type I to IV) had mean 25-OHD concentrations of $23.1 \pm 10.2 \mathrm{ng} / \mathrm{mL}$ compared to $18.9 \pm 10.1 \mathrm{ng} / \mathrm{mL}$ for women with dark skin (type V and VI).

Table 1. Maternal characteristics and vitamin D concentration at the first trimester of pregnancy.

\begin{tabular}{|c|c|c|c|}
\hline & \multicolumn{3}{|c|}{ All Women } \\
\hline & $n(\%)$ & Mean $25-\mathrm{OHD} \pm \mathrm{SD}(\mathrm{ng} / \mathrm{mL})$ & $p$-Value \\
\hline Total & 2813 & $22.2 \pm 10.3$ & \\
\hline \multicolumn{4}{|l|}{ Maternal Age (years) } \\
\hline $18-24$ & $257(9.1)$ & $19.4 \pm 9.8$ & $<0.001$ \\
\hline $25-34$ & $1845(65.6)$ & $22.3 \pm 10.2$ & \\
\hline $35+$ & $711(25.3)$ & $22.9 \pm 10.6$ & \\
\hline \multicolumn{4}{|l|}{$\operatorname{BMI}\left(\mathrm{kg} / \mathrm{m}^{2}\right)$} \\
\hline$<18.5$ & $165(5.9)$ & $21.4 \pm 10.9$ & 0.001 \\
\hline $18.5-24.9$ & $1826(65.1)$ & $22.7 \pm 10.3$ & \\
\hline $25-29.9$ & $542(19.3)$ & $21.2 \pm 10.3$ & \\
\hline $30+$ & $270(9.6)$ & $20.9 \pm 9.8$ & \\
\hline \multicolumn{4}{|l|}{ Parity } \\
\hline Nulliparous & 1339 (47.6) & $22.7 \pm 10.4$ & 0.008 \\
\hline Multiparous & $1474(52.4)$ & $21.7 \pm 10.2$ & \\
\hline \multicolumn{4}{|l|}{ Smoking During Pregnancy } \\
\hline Yes & $329(11.8)$ & $22.6 \pm 9.8$ & 0.416 \\
\hline No & $2447(88.2)$ & $22.1 \pm 10.4$ & \\
\hline \multicolumn{4}{|l|}{ Origin } \\
\hline France & $1567(55.8)$ & $23.8 \pm 9.9$ & $<0.001$ \\
\hline Other European Countries & $259(9.2)$ & $25.1 \pm 10.1$ & \\
\hline North African Countries & $463(16.5)$ & $17.8 \pm 10.1$ & \\
\hline Other African Countries & $299(10.7)$ & $19.1 \pm 10.1$ & \\
\hline Other Countries & $218(7.8)$ & $20.3 \pm 10.2$ & \\
\hline \multicolumn{4}{|l|}{ Skin Color ${ }^{\mathrm{a}}$} \\
\hline Light Skin (Type I to IV) & $2197(78.1)$ & $23.1 \pm 10.2$ & $<0.001$ \\
\hline Dark Skin (Type V to VI) & $616(21.9)$ & $18.9 \pm 10.1$ & \\
\hline \multicolumn{4}{|l|}{ Season at Blood Draw $\mathrm{b}$} \\
\hline Spring & $726(25.8)$ & $19.9 \pm 10.5$ & $<0.001$ \\
\hline Summer & $715(25.4)$ & $26.3 \pm 9.9$ & \\
\hline Autumn & $752(26.7)$ & $23.0 \pm 10.0$ & \\
\hline Winter & $620(22.0)$ & $18.9 \pm 9.2$ & \\
\hline \multicolumn{4}{|l|}{ Medical or Obstetrical History ${ }^{c}$} \\
\hline Yes & $458(16.3)$ & $21.4 \pm 10.2$ & 0.091 \\
\hline No & $2355(83.7)$ & $22.3 \pm 10.4$ & \\
\hline
\end{tabular}

${ }^{a}$ Based on the Fitzpatrick scale. ${ }^{b}$ Seasons were defined as follows: spring runs from 20 March to 19 June, summer from 20 June to 21 September, fall (autumn) from 22 September to 21 December, and winter from 22 December to 19 March. ${ }^{\mathrm{C}}$ Included diabetes, chronic hypertension, auto-immune diseases, obstetrical history of SGA infant, preterm birth, stillbirth and pre-eclampsia.

\subsection{Factors Related to Low Maternal 25-OHD Levels}

Overall, $45.1 \%$ of women had low $25-\mathrm{OHD}$ levels $<20 \mathrm{ng} / \mathrm{mL}$ in the first trimester of pregnancy. There was a higher proportion of women with low 25-OHD levels among younger women (56.8\%), and those with a BMI before pregnancy of $\geq 30 \mathrm{~kg} / \mathrm{m}^{2}(51.8 \%)$, Africans and those with a dark skin color $(60.4 \%)$ (Table 2$)$. In contrast, the proportion of women with $25-\mathrm{OHD}$ levels $<20 \mathrm{ng} / \mathrm{mL}$ was lower 
when blood draw in the first trimester of pregnancy was tested in summer $(26.3 \%)$ and in autumn $(40.7 \%)$.

Table 2. Socio-demographic, medical and blood draw characteristics related to low maternal 25-OHD concentrations $<20 \mathrm{ng} / \mathrm{mL}$ in the first trimester of pregnancy.

\begin{tabular}{|c|c|c|c|}
\hline & \multirow{2}{*}{$\begin{array}{c}\text { Total } \\
N\end{array}$} & \multicolumn{2}{|c|}{ Low Maternal 25-OHD Levels $<20 \mathrm{ng} / \mathrm{mL}$} \\
\hline & & $n / N(\%)$ & Unadjusted OR (95\% CI) \\
\hline Total & 2813 & $1268 / 2813(45.1)$ & \\
\hline \multicolumn{4}{|l|}{ Maternal Age (years) } \\
\hline $18-24$ & 257 & $146 / 257(56.8)$ & $1.73(1.29-2.30)$ \\
\hline $25-34$ & 1845 & $815 / 1845(44.2)$ & $1.04(0.87-1.23)$ \\
\hline $35+$ & 711 & $307 / 711(43.2)$ & Reference \\
\hline \multicolumn{4}{|l|}{ BMI $\left(\mathrm{kg} / \mathrm{m}^{2}\right)$} \\
\hline$<18.5$ & 165 & $81 / 165(49.1)$ & $1.29(0.93-1.77)$ \\
\hline $18.5-24.9$ & 1826 & $781 / 1826(42.8)$ & Reference \\
\hline $25-29.9$ & 542 & $259 / 542(47.8)$ & $1.22(1.01-1.48)$ \\
\hline $30+$ & 270 & $140 / 270(51.8)$ & $1.44(1.11-1.86)$ \\
\hline \multicolumn{4}{|l|}{ Parity } \\
\hline Nulliparous & 1339 & $567 / 1339(42.3)$ & $0.80(0.69-0.94)$ \\
\hline Multiparous & 1474 & $701 / 1474(47.6)$ & Reference \\
\hline \multicolumn{4}{|l|}{ Smoking during Pregnancy } \\
\hline Yes & 329 & $137 / 329(41.6)$ & $0.85(0.68-1.08)$ \\
\hline No & 2447 & $1110 / 2447(45.4)$ & Reference \\
\hline \multicolumn{4}{|l|}{ Origin } \\
\hline France & 1567 & $589 / 1567(37.6)$ & Reference \\
\hline Other European Countries & 259 & $83 / 259(32.0)$ & $0.78(0.59-1.03)$ \\
\hline North African Countries & 463 & $295 / 463(63.7)$ & $2.91(2.35-3.61)$ \\
\hline Other African Countries & 299 & $178 / 299(59.5)$ & $2.44(1.89-3.14)$ \\
\hline Other Countries & 218 & $119 / 218(54.6)$ & $1.99(1.50-2.65)$ \\
\hline \multicolumn{4}{|l|}{ Skin Color ${ }^{a}$} \\
\hline Light Skin (Type I to IV) & 2197 & $896 / 2197(40.8)$ & Reference \\
\hline Dark Skin (Type V to VI) & 616 & $372 / 616(60.4)$ & $2.21(1.84-2.65)$ \\
\hline \multicolumn{4}{|l|}{ Season at Blood Draw ${ }^{b}$} \\
\hline Spring & 726 & $404 / 726(55.6)$ & Reference \\
\hline Summer & 715 & $188 / 715(26.3)$ & $0.28(0.22-0.35)$ \\
\hline Autumn & 752 & $306 / 752(40.7)$ & $0.54(0.44-0.67)$ \\
\hline Winter & 620 & $370 / 620(59.7)$ & $1.17(0.94-1.46)$ \\
\hline \multicolumn{4}{|l|}{ Medical or Obstetrical History ${ }^{c}$} \\
\hline Yes & 458 & $224 / 458(48.9)$ & $1.20(0.98-1.46)$ \\
\hline No & 2355 & $1044 / 2355(44.3)$ & Reference \\
\hline
\end{tabular}

\footnotetext{
${ }^{a}$ Based on the Fitzpatrick scale. ${ }^{b}$ Seasons were defined as follows: spring runs from 20 March to 19 June, summer from 20 June to 21 September, fall (autumn) from 22 September to 21 December, and winter from 22 December to 19 March. ' Included diabetes, chronic hypertension, auto-immune diseases, obstetrical history of SGA infant, preterm birth, stillbirth and pre-eclampsia.
}

3.3. Association between Maternal 25-OHD Concentrations in the First Trimester of Pregnancy and Risks of Preterm and Small-for-Gestational Age Birth

Twenty-seven percent of women had 25-OHD concentrations $<15 \mathrm{ng} / \mathrm{mL}$ and $45.1 \%$ had concentrations $<20 \mathrm{ng} / \mathrm{mL}$. (Table 3) There was no difference in the means of gestational age at blood draw between preterm and term birth (12.68 \pm 0.80 vs. $12.77 \pm 0.81, p=0.144)$, and SGA and non-SGA birth $(12.73 \pm 0.76$ vs. $12.77 \pm 0.81, p=0.391)$ (results not shown). Compared to the 4 th quartile $\left(30 \mathrm{ng} / \mathrm{mL}^{+}\right)$, the adjusted odds ratio associated with 25-OHD concentrations in the 1st quartile was 1.53 (95\% CI: 0.97-2.43)) for the risk of preterm birth and 1.07 (95\% CI: 0.75-1.54) for the risk of having an SGA infant. 
Table 3. Vitamin D status in the first trimester of pregnancy and risk of preterm and small-for-gestational age status at birth in the overall sample and by skin color.

\begin{tabular}{|c|c|c|c|c|c|c|c|c|c|}
\hline \multirow{3}{*}{$\begin{array}{l}\text { 25-OHD Concentrations in the 1st } \\
\text { Trimester of Pregnancy }\end{array}$} & \multicolumn{4}{|c|}{ Gestational Age at Birth } & \multicolumn{4}{|c|}{ Birthweight } & \multirow[b]{2}{*}{$\begin{array}{l}\text { Adjusted OR } \\
\text { (CI 95\%) }\end{array}$} \\
\hline & Total & $<37$ Weeks & $\geq 37$ Weeks & $\begin{array}{l}\text { Crude OR } \\
\text { (CI 95\%) }\end{array}$ & $\begin{array}{l}\text { Adjusted OR } \\
\text { (CI 95\%) }\end{array}$ & $\begin{array}{l}<10 \text { th } \\
\text { Percentile }\end{array}$ & $\begin{array}{l}\geq 10 \text { th } \\
\text { Percentile }\end{array}$ & $\begin{array}{l}\text { Crude OR } \\
\text { (CI 95\%) }\end{array}$ & \\
\hline & $\%$ & $\%$ & $\%$ & & & $\%$ & $\%$ & & \\
\hline Overall sample n (\%) & & $189(6.7)$ & $2624(93.3)$ & & & $336(11.9)$ & $2477(88.1)$ & & \\
\hline \multicolumn{10}{|l|}{ Level Cut-Off (ng/mL) } \\
\hline$<20$ & 45.1 & 53.5 & 44.5 & $1.41(0.96-2.07)$ & $1.46(0.96-2.22)^{\mathrm{a}}$ & 46.4 & 44.9 & $1.07(0.80-1.43)$ & $1.10(0.80-1.52)^{\mathrm{a}}$ \\
\hline $20-29$ & 30.9 & 25.9 & 31.2 & $0.97(0.63-1.50)$ & $1.04(0.67-1.63)^{\mathrm{a}}$ & 30.4 & 30.9 & $1.02(0.74-1.39)$ & $1.09(0.79-1.51)^{\mathrm{a}}$ \\
\hline $\begin{array}{c}30+ \\
\text { In Ouartiles (ng/mL) }\end{array}$ & 24.1 & 20.6 & \multicolumn{4}{|c|}{ In Quartiles (ng/mL) } & 24.2 & Reference & Reference \\
\hline Q1: $<15$ & 27.0 & 34.4 & 26.6 & $1.52(1.01-2.30)$ & $1.53(0.97-2.43)^{\mathrm{a}}$ & 27.4 & 27.0 & $1.05(0.76-1.45)$ & $1.07(0.75-1.54)^{\mathrm{a}}$ \\
\hline Q2: $15-21$ & 24.1 & 25.4 & 24.0 & $1.24(0.80-1.92)$ & $1.37(0.86-2.17)^{\mathrm{a}}$ & 22.9 & 24.3 & $0.98(0.70-1.37)$ & $1.01(0.71-1.44)^{a}$ \\
\hline Q3: 22-29 & 24.7 & 19.6 & 25.1 & $0.91(0.57-1.45)$ & $0.99(0.61-1.58)^{\mathrm{a}}$ & 26.5 & 24.5 & $1.12(0.81-1.55)$ & $1.18(0.84-1.65)^{\mathrm{a}}$ \\
\hline Q4: 30+ & 24.1 & 20.6 & 24.3 & Reference & Reference & 23.2 & 24.2 & Reference & Reference \\
\hline \multicolumn{10}{|l|}{ Level Cut-Off (ng/mL) } \\
\hline$<20$ & 40.8 & 44.3 & 40.6 & $1.10(0.71-1.71)$ & $1.19(0.73-1.93)^{\mathrm{b}}$ & 40.2 & 40.8 & $0.97(0.69-1.36)$ & $1.12(0.78-1.62)^{\mathrm{b}}$ \\
\hline $20-29$ & 32.9 & 29.8 & 33.1 & $0.91(0.57-1.47)$ & $0.97(0.60-1.58)^{b}$ & 33.2 & 32.8 & $1.00(0.70-1.42)$ & $1.08(0.75-1.54)^{b}$ \\
\hline$\frac{30+}{30}$ & 26.3 & 25.9 & 26.3 & Reference & Reference & 26.6 & 26.3 & Reference & Reference \\
\hline \multicolumn{10}{|l|}{ In Quartiles (ng/mL) } \\
\hline Q1: $<15$ & 23.2 & 25.9 & 23.0 & $1.14(0.70-1.87)$ & $1.15(0.66-2.03)^{b}$ & 23.6 & 23.1 & $1.01(0.69-1.48)$ & $1.22(0.80-1.87)^{b}$ \\
\hline Q2: $15-21$ & 23.8 & 25.2 & 23.8 & $1.07(0.65-1.76)$ & $1.22(0.72-2.05)^{\mathrm{b}}$ & 20.3 & 24.3 & $0.83(0.56-1.22)$ & $0.91(0.60-1.37)^{\mathrm{b}}$ \\
\hline Q3: 22-29 & 26.6 & 22.8 & 26.9 & $0.86(0.52-1.43)$ & $0.93(0.55-1.55)^{b}$ & 29.5 & 26.3 & $1.11(0.77-1.59)$ & $1.18(0.81-1.70)^{\mathrm{b}}$ \\
\hline Q4: 30+ & 26.3 & 25.9 & 26.3 & Reference & Reference & 26.6 & 26.3 & Reference & Reference \\
\hline $\begin{array}{l}\text { Dark Skin (Type V to VI) n (\%) } \\
\text { Level cut-off (ng/mL) }\end{array}$ & \multicolumn{8}{|c|}{ Level cut-off (ng/mL) } & \\
\hline$<20$ & 60.4 & 74.1 & 59.0 & $2.43(0.93-6.31)$ & $2.63(0.95-7.27)^{\mathrm{b}}$ & 62.1 & 60.1 & $1.13(0.60-2.12)$ & $1.13(0.57-2.22)^{b}$ \\
\hline $20-29$ & 23.7 & 17.2 & 24.4 & $1.37(0.45-4.13)$ & $1.25(0.39-4.01)^{\mathrm{b}}$ & 23.2 & 23.8 & $1.06(0.51-2.19)$ & $1.20(0.56-2.60)^{b}$ \\
\hline $\begin{array}{c}30+ \\
\text { In Ouartiles (ng/mL) }\end{array}$ & 15.9 & 8.6 & 16.6 & Reference & Reference & 14.7 & 16.1 & Reference & Reference \\
\hline Q1: $<15$ & 40.9 & 53.4 & 39.6 & $2.61(0.98-6.91)$ & $2.89(1.02-8.18)^{b}$ & 36.8 & 41.6 & $0.97(0.49-1.88)$ & $0.94(0.45-1.92)^{b}$ \\
\hline Q2: 15-21 & 25.2 & 25.9 & 25.1 & $1.99(0.70-5.67)$ & $1.89(0.62-5.78)^{b}$ & 29.6 & 24.4 & $1.32(0.65-2.65)$ & $1.48(0.69-3.14)^{b}$ \\
\hline Q3: 22-29 & 18.0 & 12.1 & 18.6 & $1.25(0.38-4.08)$ & $1.24(0.35-4.30)^{\mathrm{b}}$ & 18.9 & 17.8 & $1.16(0.54-2.47)$ & $1.25(0.56-2.77)^{b}$ \\
\hline Q4: 30+ & 15.9 & 8.6 & 16.7 & Reference & Reference & 14.7 & 16.2 & Reference & Reference \\
\hline
\end{tabular}

before pregnancy, medical or obstetrical history, smoking, ethnicity and season at blood draw. 
The interaction between skin color and vitamin $\mathrm{D}$ concentrations was significant for the risk of preterm birth $(p$ value $=0.050)$ but not for SGA $(p$ value $=0.708)$. Analyses stratified by skin color showed that women with light skin had no excess risk of preterm birth, whereas the risk of preterm birth for women with dark skin (type V to VI) was increased for the first quartile of 25-OHD (aOR $=2.89$ (95\% CI: 1.02-8.18)). Results were similar using clinical cut-offs, with an aOR of 2.63 (95\% CI: 0.95-7.27) for $25-\mathrm{OHD}$ concentrations $<20 \mathrm{ng} / \mathrm{mL}$ compared to those with $25-\mathrm{OH}$ levels $>30 \mathrm{ng} / \mathrm{mL}$. No association was observed for SGA using quartiles or clinical cut-offs. Analyses with birthweight and gestational age as continuous variables confirmed the absence of an association between low 25-OHD levels with birthweight in the overall sample and an interaction with skin colour for gestational age $(p=0.05)$. (Table S1)

\subsection{Association between 25-OHD Maternal Concentrations and Risks of Preterm and SGA Birth Using Restricted Cubic Splines}

Restricted cubic splines were used to investigate the association between maternal 25-OHD concentrations and the risk of preterm and SGA birth adjusted for maternal age, parity, BMI before pregnancy, medical or obstetrical history, smoking, ethnicity, skin color and season at blood draw overall. Figures show that the risk of preterm birth and having an SGA infant were not different, regardless of maternal vitamin D concentrations in the overall sample and for women with light skin color. (Figures 2 and 3) For women with dark skin color, the risk of preterm birth was elevated for the lowest maternal 25-OHD levels and no association was found with the risk of SGA birth (Figure 4).
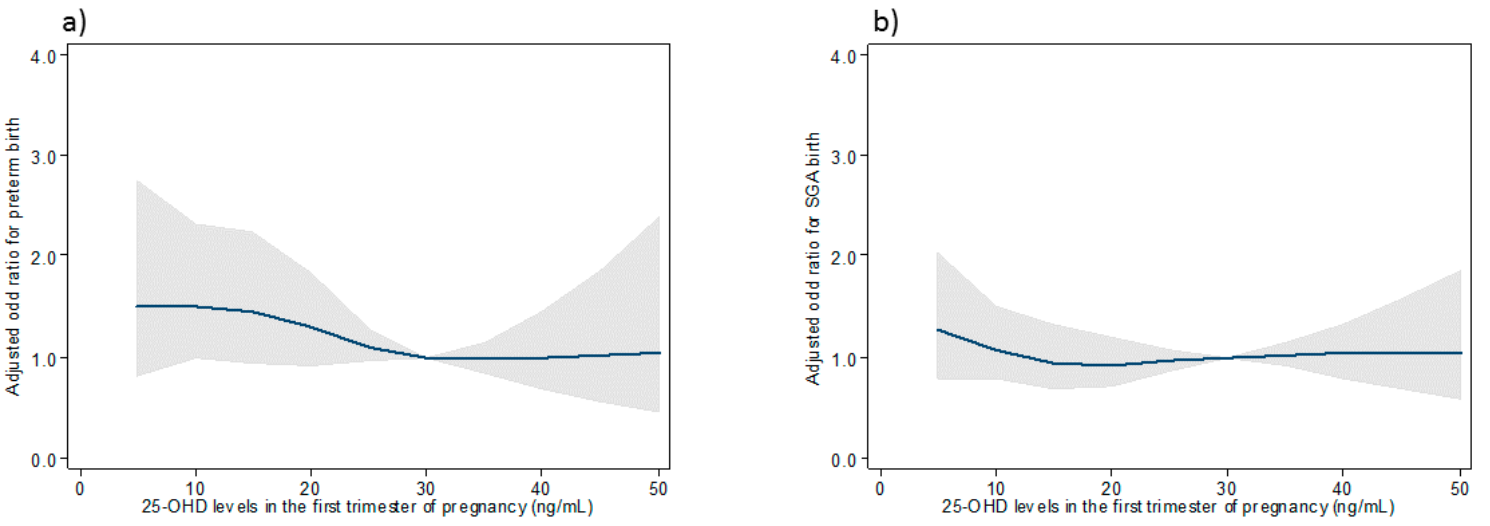

Figure 2. Association between 25-OHD concentrations in the first trimester of pregnancy and the risk of preterm (a) and SGA birth (b) in the overall sample.

a)

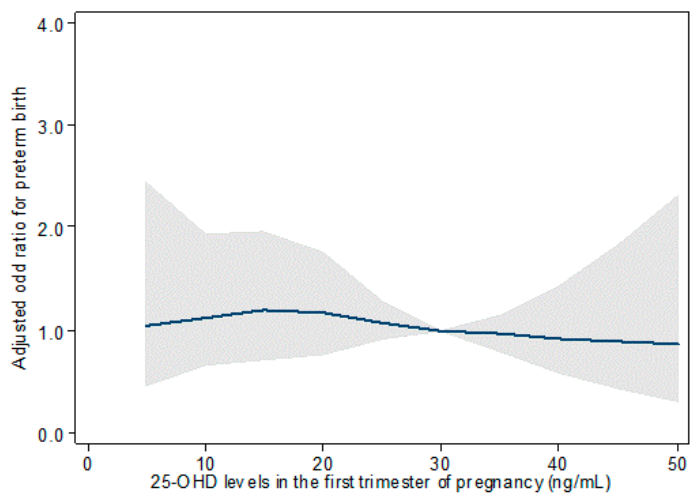

b)

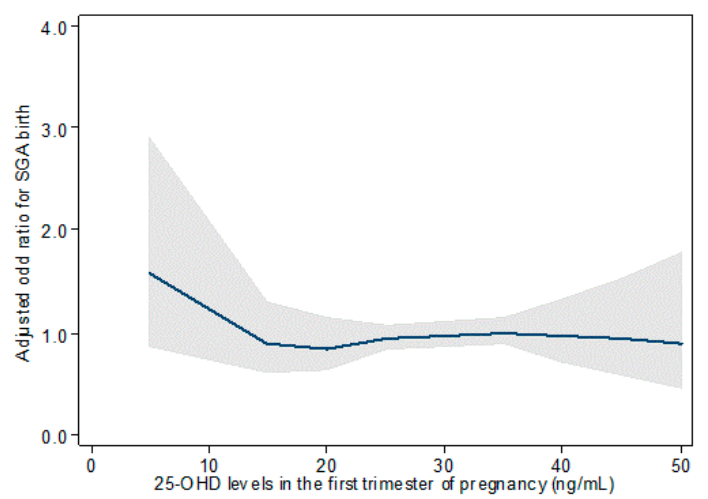

Figure 3. Association between 25-OHD concentrations in the first trimester of pregnancy and the risk of preterm (a) and SGA birth (b) for women with light skin (type I to type IV). 
a)

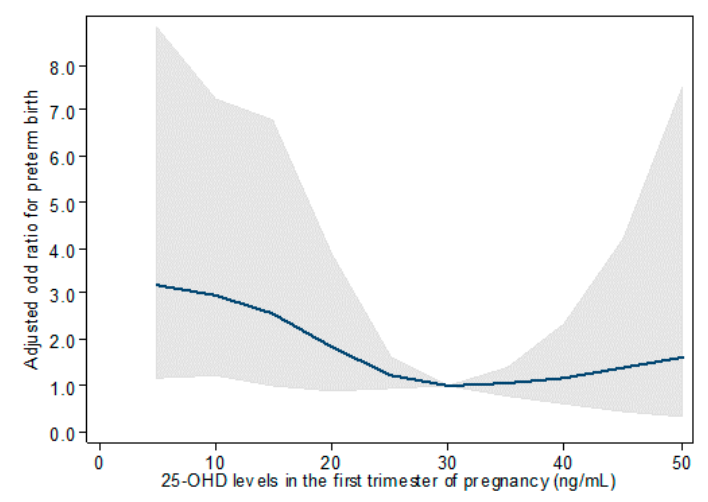

b)

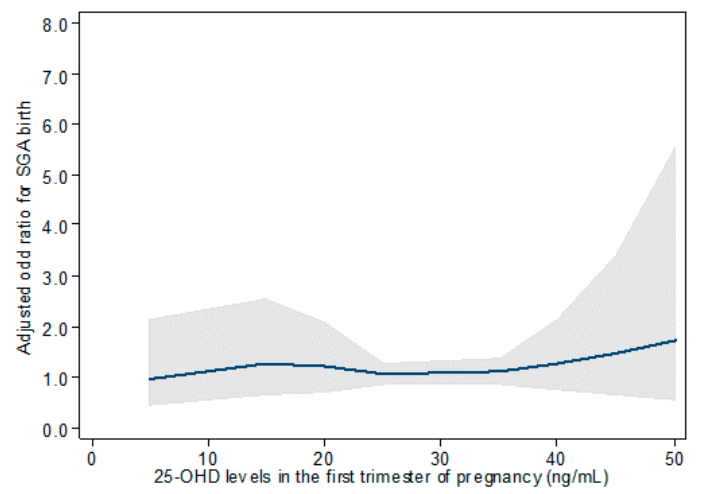

Figure 4. Association between 25-OHD concentrations in the first trimester of pregnancy and the risk of preterm (a) and SGA birth (b) for women with dark skin (type V to type VI).

\section{Discussion}

In our cohort, almost half of pregnant women had 25-OHD concentrations in the first trimester of pregnancy below the lower clinical cut-off point of $<20 \mathrm{ng} / \mathrm{mL}$, one-quarter had 25-OHD concentrations of $<15 \mathrm{ng} / \mathrm{mL}$, while only $24 \%$ of women had $25-\mathrm{OHD}$ levels above $30 \mathrm{ng} / \mathrm{mL}$. No association was found between low maternal vitamin D concentrations and the risk of preterm and SGA birth in the overall sample and among women with a lighter skin. In contrast, an increased risk of preterm birth, but not SGA, was observed for women with darker skin.

Our study has several strengths. We used data from a large multicentre prospective cohort explicitly designed to investigate the association between maternal vitamin $\mathrm{D}$ concentrations and perinatal outcomes $[27,28]$. All pregnant women had a blood draw between 10 and 14 weeks of gestation, as opposed to other studies that used wide gestational age limits for the assessment of 25-ODH concentrations [12-14]. France and Belgium have a temperate climate and variability in sun exposure was also limited because participating centres were at similar latitudes [27]. Also, in contrast to many previous analyses, we had standardised measures of skin color. Limitations include the observational design, which means it is not possible to demonstrate a causal relationship. We could not consider the potential for residual confounding remains and, notably, the mother's socioeconomic characteristics. However, smoking, prepregnancy BMI and ethnicity are related to socioeconomic position [44] and we included them in our models. Finally, the size of our sample was too small to investigate preterm birth subtypes (spontaneous or induced preterm birth).

Our aim was to assess the benefit of vitamin D supplementation in early pregnancy on perinatal outcomes and, thus, we did not examine the changes in vitamin D levels between the first and the third trimester of pregnancy. This change was examined in a previous analysis using the FEPED cohort. The increase of 25-OHD levels was estimated to $6.3 \mathrm{ng} / \mathrm{mL}(\mathrm{SD}=12.6)$ and $8.5(\mathrm{SD}=11.5)$ in women with pre-eclampsia and in those with no pre-eclampsia [28]. In our study, we found that almost half of women had vitamin D deficiency $(<20 \mathrm{ng} / \mathrm{mL})$ in their first trimester of pregnancy; our study adds to limited research showing that vitamin D deficiency is highly prevalent among pregnant women $[25,26,45,46]$. A Belgian survey estimated that $82 \%$ of pregnant women had a vitamin D concentration $<30 \mathrm{ng} / \mathrm{mL}$ in their first trimester of pregnancy, a little higher than the $75 \%$ in our study [47].

There was a higher proportion of women with low 25-OHD levels $<20 \mathrm{ng} / \mathrm{mL}$ in the first trimester of pregnancy among obese women, Africans, darker skin colored and based on season at blood draw. Vitamin $\mathrm{D}$ absorption depends on body fat, skin pigmentation and sun exposure and these characteristics are thus well-known risks factors for vitamin D deficiency $[1,26,48]$.

We investigated two pregnancy outcomes previously associated with vitamin D concentrations and for which plausible biological mechanisms have been suggested. Vitamin D could play a role in the 
regulation of genes involved in trophoblast invasion and in the angiogenesis for placenta implantation that could impact on fetal growth. However, our results related to SGA do not support an association with maternal vitamin D levels, corroborating a number of previous studies [11,23] but contrasting with others, including the results of the Cochrane Collaboration [5,9,49]. Our results also go against two studies showing an association with SGA among white, but not black women [14,15]. In addition, an increase in the production of inflammatory cytokines has been suggested in pregnant women with low vitamin D levels and this could increase the risk of preterm birth. Vitamin D is also involved in the immune system and low maternal vitamin D levels could be associated with bacterial vaginosis, which is a risk factor of preterm birth [50]. In our study, we found an elevated, but not significant effect in the overall population that reflected a high odds ratio, over two, among women with darker skin, and no association among women with lighter skin. This result similarly conflicts with multiple studies, including several meta-analyses of observational studies of preterm birth that have found an impact in general samples including women with light and dark skin [5,51]. However, our results are concordant with a previous study from the United States stratifying on race/ethnicity that showed the protective effects of vitamin $\mathrm{D}$ for spontaneous preterm births among black women, but not white women [13].

Our results, taken together with the body of conflicting literature on vitamin D and pregnancy outcomes, including the high study heterogeneity in meta-analyses, suggests that the association of vitamin $\mathrm{D}$ concentrations and these pregnancy outcomes may depend on the populations studied [5,9-11,49]. The differences between populations could be the result of residual confounding, as maternal vitamin D status depends on many factors, including diet and nutrition, vitamin supplementation, physical activity, socioeconomic status and race, all of which are independently related to pregnancy outcome. This means that some factors were inadequately measured and led to a spurious association [52]. However, population variation in sensitivity to vitamin deficiency may also explain discordant results, perhaps due to differences in the aetiology of preterm and SGA birth across populations. In the study showing an effect of vitamin D deficiency on risk of spontaneous preterm births among black women, the authors note that preterm deliveries occurring among black women have been found to be more often associated with infection [13]. In contrast, black women could be less sensitive to vitamin D deficiency, due to renal and skeletal adaptation [53], which was put forth as an explanation for the absence of association between a low vitamin D level and risk of SGA in black women $[14,15]$. Finally, the effects of vitamin D on birth outcomes may be different according to the timing of vitamin D assessment. In the meta-analysis of Chen et al., a positive association was found between maternal vitamin D deficiency and the risk of having an SGA infant (OR = 1.59 (95\% CI: 1.14-2.22)) [49]. However, this association was no longer significant in the subgroup analysis of studies that measured vitamin D strictly during the first trimester of pregnancy (OR $=1.29$ (95\% CI: 0.95-1.74)). Further research, to assess biological pathways in light of these questions, is needed to design more informative interventional and observational studies.

In conclusion, our study does not provide support for a common biological pathway linking vitamin D concentrations in the first trimester of pregnancy to risks of preterm or SGA birth. However, further investigation is needed on potential differences in preterm birth risks among women with darker skin color.

Supplementary Materials: The following are available online at http://www.mdpi.com/2072-6643/11/12/3042/s1, Table S1: Association between vitamin D status in the first trimester of pregnancy and gestational age and birthweight as continuous variables in the overall sample and by skin color.

Author Contributions: Conceptualization, A.B. (Alexandra Benachi), A.B. (Amandine Baptiste), C.E. and J.-C.S.; methodology, A.B. (Alexandra Benachi) and C.E.; validation, I.M., J.Z. and A.B. (Alexandra Benachi); formal analysis, I.M. and J.Z.; investigation, A.B. (Alexandra Benachi), V.T., M.-V.S., J.J., J.-M.J. and N.W.; data curation, C.E.; writing-original draft preparation, I.M., J.Z. and A.B. (Alexandra Benachi); writing-review and editing, I.M., J.Z. and A.B. (Alexandra Benachi); visualization, A.B. (Alexandra Benachi); supervision, J.Z. and A.B. (Alexandra Benachi); project administration, C.E.; funding acquisition, A.B. (Alexandra Benachi). 
Funding: This research was funded by Grant from the Programme Hospitalier de Recherche Publique-PHRC national 2010 (Ministry of Health e AOM10113).

Acknowledgments: We thank S. Albert, V. Buth, V. da Costa, S. Larrède, E. Etienne, L. Peaudecerf et I. Rieger for monitoring the data. A. Bellino and M. Delattre for coordinating the study. We are grateful to the doctors, midwives and nurses for collecting information from patients. We would also like to thank the "Centre de Ressources Biologiques", Centre Hospitalier Intercommunal de Créteil for the management and storage of biospecimens.

Conflicts of Interest: J.-C.S. reports lecture fees and/or travel/hotel expenses from DiaSorin, Roche Diagnostics, Abbott, Amgen, Shire, MSD, Lilly, and Rottapharm/Meda. The other authors report no conflict of interest. The funders had no role in the design of the study; in the collection, analyses, or interpretation of data; in the writing of the manuscript, or in the decision to publish the results.

\section{References}

1. Holick, M.F.; Chen, T.C. Vitamin D deficiency: A worldwide problem with health consequences. Am. J. Clin. Nutr. 2008, 87, 1080S-1086S. [CrossRef] [PubMed]

2. Hensel, K.J.; Randis, T.M.; Gelber, S.E.; Ratner, A.J. Pregnancy-specific association of vitamin D deficiency and bacterial vaginosis. Am. J. Obstet. Gynecol. 2011, 204, 41e1-9. [CrossRef] [PubMed]

3. Hillier, S.L.; Nugent, R.P.; Eschenbach, D.A.; Krohn, M.A.; Gibbs, R.S.; Martin, D.H.; Cotch, M.F.; Edelman, R.; Pastorek, J.G., 2nd; Rao, A.V.; et al. Association between bacterial vaginosis and preterm delivery of a low-birth-weight infant. The Vaginal Infections and Prematurity Study Group. N. Engl. J. Med. 1995, 333, 1737-1742. [CrossRef] [PubMed]

4. Specker, B. Vitamin D requirements during pregnancy. Am. J. Clin. Nutr. 2004, 80, 1740S-1747S. [CrossRef]

5. Aghajafari, F.; Nagulesapillai, T.; Ronksley, P.E.; Tough, S.C.; O’Beirne, M.; Rabi, D.M. Association between maternal serum 25-hydroxyvitamin $\mathrm{D}$ level and pregnancy and neonatal outcomes: Systematic review and meta-analysis of observational studies. BMJ 2013, 346, f1169. [CrossRef]

6. Wei, S.Q.; Qi, H.P.; Luo, Z.C.; Fraser, W.D. Maternal vitamin D status and adverse pregnancy outcomes: A systematic review and meta-analysis. J. Matern. Fetal Neonatal Med. 2013, 26, 889-899. [CrossRef]

7. Flenady, V.; Koopmans, L.; Middleton, P.; Froen, J.F.; Smith, G.C.; Gibbons, K.; Coory, M.; Gordon, A.; Ellwood, D.; McIntyre, H.D.; et al. Major risk factors for stillbirth in high-income countries: A systematic review and meta-analysis. Lancet 2011, 377, 1331-1340. [CrossRef]

8. Nguyen, T.P.; Yong, H.E.; Chollangi, T.; Borg, A.J.; Brennecke, S.P.; Murthi, P. Placental vitamin D receptor expression is decreased in human idiopathic fetal growth restriction. J. Mol. Med. 2015, 93, 795-805. [CrossRef]

9. De-Regil, L.M.; Palacios, C.; Lombardo, L.K.; Pena-Rosas, J.P. Vitamin D supplementation for women during pregnancy. Cochrane Database Syst. Rev. 2016, CD008873. [CrossRef]

10. Roth, D.E.; Leung, M.; Mesfin, E.; Qamar, H.; Watterworth, J.; Papp, E. Vitamin D supplementation during pregnancy: State of the evidence from a systematic review of randomised trials. BMJ 2017, 359, j5237. [CrossRef]

11. Perez-Lopez, F.R.; Pasupuleti, V.; Mezones-Holguin, E.; Benites-Zapata, V.A.; Thota, P.; Deshpande, A.; Hernandez, A.V. Effect of vitamin D supplementation during pregnancy on maternal and neonatal outcomes: A systematic review and meta-analysis of randomized controlled trials. Fertil. Steril. 2015, 103, 1278-1288.e4. [CrossRef] [PubMed]

12. Bodnar, L.M.; Platt, R.W.; Simhan, H.N. Early-pregnancy vitamin D deficiency and risk of preterm birth subtypes. Obstet. Gynecol. 2015, 125, 439-447. [CrossRef] [PubMed]

13. Bodnar, L.M.; Klebanoff, M.A.; Gernand, A.D.; Platt, R.W.; Parks, W.T.; Catov, J.M.; Simhan, H.N. Maternal vitamin D status and spontaneous preterm birth by placental histology in the US Collaborative Perinatal Project. Am. J. Epidemiol. 2014, 179, 168-176. [CrossRef] [PubMed]

14. Bodnar, L.M.; Catov, J.M.; Zmuda, J.M.; Cooper, M.E.; Parrott, M.S.; Roberts, J.M.; Marazita, M.L.; Simhan, H.N. Maternal serum 25-hydroxyvitamin D concentrations are associated with small-for-gestational age births in white women. J. Nutr. 2010, 140, 999-1006. [CrossRef]

15. Ertl, R.; Yu, C.K.; Samaha, R.; Akolekar, R.; Nicolaides, K.H. Maternal serum vitamin D at 11-13 weeks in pregnancies delivering small for gestational age neonates. Fetal Diagn. Ther. 2012, 31, 103-108. [CrossRef] 
16. Burris, H.H.; Rifas-Shiman, S.L.; Camargo, C.A., Jr.; Litonjua, A.A.; Huh, S.Y.; Rich-Edwards, J.W.; Gillman, M.W. Plasma 25-hydroxyvitamin D during pregnancy and small-for-gestational age in black and white infants. Ann. Epidemiol. 2012, 22, 581-586. [CrossRef]

17. Leffelaar, E.R.; Vrijkotte, T.G.; van Eijsden, M. Maternal early pregnancy vitamin D status in relation to fetal and neonatal growth: Results of the multi-ethnic Amsterdam Born Children and their Development cohort. Br. J. Nutr. 2010, 104, 108-117. [CrossRef]

18. Flood-Nichols, S.K.; Tinnemore, D.; Huang, R.R.; Napolitano, P.G.; Ippolito, D.L. Vitamin D deficiency in early pregnancy. PLoS ONE 2015, 10, e0123763. [CrossRef]

19. Baker, A.M.; Haeri, S.; Camargo, C.A., Jr.; Stuebe, A.M.; Boggess, K.A. A nested case-control study of first-trimester maternal vitamin D status and risk for spontaneous preterm birth. Am. J. Perinatol. 2011, 28, 667-672. [CrossRef]

20. Fernandez-Alonso, A.M.; Dionis-Sanchez, E.C.; Chedraui, P.; Gonzalez-Salmeron, M.D.; Perez-Lopez, F.R.; Spanish Vitamin D and Women's Health Research Group. First-trimester maternal serum 25-hydroxyvitamin D(3) status and pregnancy outcome. Int. J. Gynaecol. Obstet. 2012, 116, 6-9. [CrossRef]

21. Rodriguez, A.; Garcia-Esteban, R.; Basterretxea, M.; Lertxundi, A.; Rodriguez-Bernal, C.; Iniguez, C.; Rodriguez-Dehli, C.; Tardon, A.; Espada, M.; Sunyer, J.; et al. Associations of maternal circulating 25-hydroxyvitamin D3 concentration with pregnancy and birth outcomes. BJOG Int. J. Obstet. Gynaecol. 2015, 122, 1695-1704. [CrossRef] [PubMed]

22. Thorp, J.M.; Camargo, C.A.; McGee, P.L.; Harper, M.; Klebanoff, M.A.; Sorokin, Y.; Varner, M.W.; Wapner, R.J.; Caritis, S.N.; Iams, J.D.; et al. Vitamin D status and recurrent preterm birth: A nested case-control study in high-risk women. BJOG Int. J. Obstet. Gynaecol. 2012, 119, 1617-1623. [CrossRef] [PubMed]

23. Roth, D.E.; Morris, S.K.; Zlotkin, S.; Gernand, A.D.; Ahmed, T.; Shanta, S.S.; Papp, E.; Korsiak, J.; Shi, J.; Islam, M.M.; et al. Vitamin D Supplementation in Pregnancy and Lactation and Infant Growth. N. Engl. J. Med. 2018, 379, 535-546. [CrossRef] [PubMed]

24. Miliku, K.; Vinkhuyzen, A.; Blanken, L.M.; McGrath, J.J.; Eyles, D.W.; Burne, T.H.; Hofman, A.; Tiemeier, H.; Steegers, E.A.; Gaillard, R.; et al. Maternal vitamin D concentrations during pregnancy, fetal growth patterns, and risks of adverse birth outcomes. Am. J. Clin. Nutr. 2016, 103, 1514-1522. [CrossRef]

25. Bodnar, L.M.; Simhan, H.N.; Powers, R.W.; Frank, M.P.; Cooperstein, E.; Roberts, J.M. High prevalence of vitamin D insufficiency in black and white pregnant women residing in the northern United States and their neonates. J. Nutr. 2007, 137, 447-452. [CrossRef]

26. Richard, A.; Rohrmann, S.; Quack Lotscher, K.C. Prevalence of Vitamin D Deficiency and Its Associations with Skin Color in Pregnant Women in the First Trimester in a Sample from Switzerland. Nutrients 2017, 9 , 260. [CrossRef]

27. Courbebaisse, M.; Souberbielle, J.C.; Baptiste, A.; Taieb, J.; Tsatsaris, V.; Guibourdenche, J.; Senat, M.V.; Haidar, H.; Jani, J.; Guizani, M.; et al. Vitamin D status during pregnancy and in cord blood in a large prospective French cohort. Clin. Nutr. 2018, 38, 2136-2144. [CrossRef]

28. Benachi, A.; Baptiste, A.; Taieb, J.; Tsatsaris, V.; Guibourdenche, J.; Senat, M.V.; Haidar, H.; Jani, J.; Guizani, M.; Jouannic, J.M.; et al. Relationship between vitamin D status in pregnancy and the risk for preeclampsia: A nested case-control study. Clin. Nutr. 2019. [CrossRef]

29. Fitzpatrick, T.B. The validity and practicality of sun-reactive skin types I through VI. Arch. Dermatol. 1988, 124, 869-871. [CrossRef]

30. Ego, A.; Prunet, C.; Lebreton, E.; Blondel, B.; Kaminski, M.; Goffinet, F.; Zeitlin, J. [Customized and non-customized French intrauterine growth curves. I-Methodology]. J. Gynecol. Obstet. Biol. Reprod. 2016, 45, 155-164. [CrossRef]

31. Vayssiere, C.; Haumonte, J.B.; Chantry, A.; Coatleven, F.; Debord, M.P.; Gomez, C.; Le Ray, C.; Lopez, E.; Salomon, L.J.; Senat, M.V.; et al. Prolonged and post-term pregnancies: Guidelines for clinical practice from the French College of Gynecologists and Obstetricians (CNGOF). Eur. J. Obstet. Gynecol. Reprod. Biol. 2013, 169, 10-16. [CrossRef] [PubMed]

32. Hollis, B.W.; Kamerud, J.Q.; Selvaag, S.R.; Lorenz, J.D.; Napoli, J.L. Determination of vitamin D status by radioimmunoassay with an 125I-labeled tracer. Clin. Chem. 1993, 39, 529-533. [PubMed]

33. Harvey, N.C.; Holroyd, C.; Ntani, G.; Javaid, K.; Cooper, P.; Moon, R.; Cole, Z.; Tinati, T.; Godfrey, K.; Dennison, E.; et al. Vitamin D supplementation in pregnancy: A systematic review. Health Technol. Assess. 2014, 18, 1-190. [CrossRef] [PubMed] 
34. Holick, M.F.; Binkley, N.C.; Bischoff-Ferrari, H.A.; Gordon, C.M.; Hanley, D.A.; Heaney, R.P.; Murad, M.H.; Weaver, C.M.; Endocrine, S. Evaluation, treatment, and prevention of vitamin D deficiency: An Endocrine Society clinical practice guideline. J. Clin. Endocrinol. Metab. 2011, 96, 1911-1930. [CrossRef]

35. Nassar, N.; Halligan, G.H.; Roberts, C.L.; Morris, J.M.; Ashton, A.W. Systematic review of first-trimester vitamin D normative levels and outcomes of pregnancy. Am. J. Obstet. Gynecol. 2011, 205, 208.e1-208.e7. [CrossRef]

36. Haute Autorité de Santé. Recommandations Professionnelles. Comment Mieux Informer les Femmes Enceintes? Haute Autorité de Santé: Saint-Denis, France, 2005.

37. Bodnar, L.M.; Simhan, H.N. The prevalence of preterm birth and season of conception. Paediatr. Perinat. Epidemiol. 2008, 22, 538-545. [CrossRef]

38. Lee, S.J.; Steer, P.J.; Filippi, V. Seasonal patterns and preterm birth: A systematic review of the literature and an analysis in a London-based cohort. BJOG Int. J. Obstet. Gynaecol. 2006, 113, 1280-1288. [CrossRef]

39. Darrow, L.A.; Strickland, M.J.; Klein, M.; Waller, L.A.; Flanders, W.D.; Correa, A.; Marcus, M.; Tolbert, P.E. Seasonality of birth and implications for temporal studies of preterm birth. Epidemiology 2009, 20, 699-706. [CrossRef]

40. Avalos, L.A.; Chen, H.; Li, D.K.; Basu, R. The impact of high apparent temperature on spontaneous preterm delivery: A case-crossover study. Environ. Health 2017, 16, 5. [CrossRef]

41. Kistka, Z.A.; Palomar, L.; Lee, K.A.; Boslaugh, S.E.; Wangler, M.F.; Cole, F.S.; DeBaun, M.R.; Muglia, L.J. Racial disparity in the frequency of recurrence of preterm birth. Am. J. Obstet. Gynecol. 2007, 196, 131e-136e. [CrossRef]

42. Howard, D.L.; Marshall, S.S.; Kaufman, J.S.; Savitz, D.A. Variations in low birth weight and preterm delivery among blacks in relation to ancestry and nativity: New York City, 1998-2002. Pediatrics 2006, 118, e1399-e1405. [CrossRef] [PubMed]

43. Slaughter-Acey, J.C.; Sneed, D.; Parker, L.; Keith, V.M.; Lee, N.L.; Misra, D.P. Skin Tone Matters: Racial Microaggressions and Delayed Prenatal Care. Am. J. Prev. Med. 2019, 57, 321-329. [CrossRef] [PubMed]

44. Wise, J. UK survey confirms link between deprivation and smoking. BMJ 2014, 348, g2184. [CrossRef] [PubMed]

45. Ginde, A.A.; Sullivan, A.F.; Mansbach, J.M.; Camargo, C.A., Jr. Vitamin D insufficiency in pregnant and nonpregnant women of childbearing age in the United States. Am. J. Obstet. Gynecol. 2010, 202. [CrossRef] [PubMed]

46. Lee, J.M.; Smith, J.R.; Philipp, B.L.; Chen, T.C.; Mathieu, J.; Holick, M.F. Vitamin D deficiency in a healthy group of mothers and newborn infants. Clin. Pediatrics 2007, 46, 42-44. [CrossRef] [PubMed]

47. Vandevijvere, S.; Amsalkhir, S.; Van Oyen, H.; Moreno-Reyes, R. High prevalence of vitamin D deficiency in pregnant women: A national cross-sectional survey. PLoS ONE 2012, 7, e43868. [CrossRef] [PubMed]

48. Holick, M.F. Vitamin D deficiency. N. Engl. J. Med. 2007, 357, 266-281. [CrossRef]

49. Chen, Y.; Zhu, B.; Wu, X.; Li, S.; Tao, F. Association between maternal vitamin D deficiency and small for gestational age: Evidence from a meta-analysis of prospective cohort studies. BMJ Open 2017, 7, e016404. [CrossRef]

50. Bodnar, L.M.; Krohn, M.A.; Simhan, H.N. Maternal vitamin D deficiency is associated with bacterial vaginosis in the first trimester of pregnancy. J. Nutr. 2009, 139, 1157-1161. [CrossRef]

51. Qin, L.L.; Lu, F.G.; Yang, S.H.; Xu, H.L.; Luo, B.A. Does Maternal Vitamin D Deficiency Increase the Risk of Preterm Birth: A Meta-Analysis of Observational Studies. Nutrients 2016, 8, 301. [CrossRef]

52. Kaufman, J.S.; Cooper, R.S.; McGee, D.L. Socioeconomic status and health in blacks and whites: The problem of residual confounding and the resiliency of race. Epidemiology 1997, 8, 621-628. [CrossRef] [PubMed]

53. Cosman, F.; Nieves, J.; Dempster, D.; Lindsay, R. Vitamin D economy in blacks. J. Bone Miner. Res. 2007, 22 (Suppl. 2), V34-V38. [CrossRef] [PubMed]

(C) 2019 by the authors. Licensee MDPI, Basel, Switzerland. This article is an open access article distributed under the terms and conditions of the Creative Commons Attribution (CC BY) license (http://creativecommons.org/licenses/by/4.0/). 